\title{
Reflexões sobre o Fator de Impacto
}

\section{Thoughts about the Impact Factor}

Tiago VILLANUEVA $\triangle^{1}$, Helena DONATO ${ }^{1,2}$, Pedro ESCADA $^{1,3}$, Carla de SOUSA ${ }^{1}$, Miguel REIS ${ }^{1}$, Rui MATOS ${ }^{1}$

Acta Med Port 2020 Oct;33(10):633-634 - https://doi.org/10.20344/amp.14773

\begin{abstract}
Palavras-chave: Fator de Impacto de Revistas; Revistas
Keywords: Journal Impact Factor; Periodicals as Topic
\end{abstract}

Por entre as constantes e desoladoras notícias sobre o aumento do número de casos, internamentos, óbitos e surtos da pandemia de COVID-19, em Portugal e no resto do mundo, tivemos uma boa notícia no final do mês de Junho, nomeadamente a subida de $8 \%$ do fator de impacto $(\mathrm{FI})$ da Acta Médica Portuguesa (AMP), de 0,581 para 0,628.

Os editores de revistas científicas médicas sabem que uma métrica como o fator de impacto de uma revista não reflete necessariamente a qualidade dos respetivos processos editoriais ou o rigor e relevância clínica e científica dos conteúdos que são publicados. No entanto, é uma métrica a que as equipas editoriais não podem ficar indiferentes, por vários motivos. Por um lado, porque norteia em parte as decisões dos autores sobre onde submeter os seus artigos, o que gera uma autêntica cadeia alimentar, recebendo as revistas de fator impacto menor os artigos que foram rejeitados pelas revistas com fator de impacto mais elevado (Mathew effect - the rich get richer). Por outro lado, porque o factor de impacto de uma revista científica é uma das métricas que conta para a progressão na carreira académica em muitas instituições pelo mundo fora. Como é fácil de usar, os avaliadores adoram usá-lo para avaliar o output científico.

Há, portanto, uma pressão e um incentivo natural para as revistas tornarem os seus $\mathrm{FI}$ mais competitivos, ainda que as estratégias para lá chegar não impliquem necessariamente uma melhoria na qualidade global da revista. Assim sendo, somos de opinião que as revistas não devem valorizar apenas o $\mathrm{FI}$, mas também prestar atenção a outras métricas como o número de acessos e downloads de artigos, partilhas e citações em redes sociais, e mesmo outros indicadores não tão tangíveis ou quantificáveis, como o feedback de inquéritos aos leitores. ${ }^{1}$

A nível interno, o $\mathrm{Fl}$ acaba naturalmente por impor uma certa disciplina em relação ao número de artigos que se publica, pois o denominador (o número de artigos publicados nos dois anos anteriores ao ano em que são contabilizadas as citações) é um dos aspetos que as equipas editoriais mais facilmente podem de facto controlar. É claro que todas as revistas querem também ver o numerador do cálculo do seu $\mathrm{FI}$ (o número de citações num determinado ano) aumentar de ano para ano, mas essa é uma evolução muito mais difícil de controlar, não existindo propriamente um método estruturado para a assegurar. Daí que a seleção de artigos acabe, portanto, por se basear muito na experiência e instinto editorial dos editores, dando prioridade a conteúdos que consideram com elevado potencial de citação.

No entanto, existem algumas estratégias que podem aumentar a probabilidade de potenciar o numerador. ${ }^{2} \mathrm{Em}$ primeiro lugar, a publicação de bons editoriais, comentários e cartas ao editor, que podem gerar citações mas não pressionam o denominador, porque normalmente são excluídos do mesmo. Por outro lado, pode ser boa ideia convidar autores, nomeadamente líderes de opinião, a escrever artigos de perspectiva e/ou revisão para a revista, já que, em geral, tendem a ser citados muito acima da média. A publicação de artigos metodológicos pode também surtir efeitos semelhantes, pois os autores que utilizem os métodos neles descritos têm de os citar. O mesmo princípio se aplica na aposta em áreas temáticas com maior potencial de citação, como por exemplo a cardiologia ou a oncologia. Por outro lado, os artigos com presumível maior potencial de citação podem beneficiar se forem publicados logo no início do ano, alargando assim, a janela de citação.

É também fundamental promover o aumento da visibilidade da revista, quer através da dinamização da presença da revista nas redes sociais (hoje em dia o Twitter é particularmente importante) quer através da divulgação dos conteúdos mais relevantes em redes e círculos clínico-académicos, ou mesmo através do estabelecimento de parcerias. Essa disseminação encontra-se, com frequência, na origem da visibilidade que alguns artigos, sobretudo os artigos originais, alcançam junto dos media, pelo que também é importante existir uma articulação regular e fluida entre a revista e os órgãos de comunicação social, idealmente através da elaboração de comunicados de imprensa. A AMP tem estabelecido parcerias com entidades como a Tonic App ou a Uphill com vista a ampliar o alcance dos seus conteúdos. Com idêntico objetivo em vista, a secção AMP-Student tem estabelecido ao longo dos anos

1. Acta Médica Portuguesa. Ordem dos Médicos. Lisboa. Portugal.

2. Serviço de Documentação e Informação Científica. Centro Hospitalar e Universitário de Coimbra. Coimbra. Portugal.

3. NOVA Medical School. Universidade NOVA de Lisboa. Lisboa. Portugal.

$\triangle$ Autor correspondente: Tiago Villanueva. tiago.villanueva@ordemdosmedicos.pt

Recebido: 20 de agosto de 2020 - Aceite: 24 de agosto de 2020 | Copyright $\odot$ Ordem dos Médicos 2020 
inúmeras parcerias com diversos congressos científicos para estudantes de Medicina.

$\mathrm{Na}$ AMP estamos atentos ao nosso fator de impacto e, como qualquer outra revista, queremos naturalmente vê-lo sempre a subir. Contudo, é para nós evidente que ele constitui apenas uma de muitas métricas e indicadores existentes, uma fórmula matemática provavelmente sobrevalorizada. Acreditamos que a sua progressão não é necessariamente um sinal de evolução da qualidade da

\section{REFERÊNCIAS}

1. Brito D, Villanueva T, Sousa C, Nunes AB, Duarte S, Reis M. A perspectiva dos nossos leitores: destaques do primeiro questionário aos leitores da Acta Médica Portuguesa. Acta Med Port. 2019;32:623-4.

2. Donato $\mathrm{H}$. Understanding journal evaluation and strategies to increase impact. Rev Port Pneumol. 2016;22:67-9. revista. As Recommendations of Scholarly Work in Medical Journals do International Committee of Medical Journal Editors, seguidas por centenas de revistas na área da biomedicina, e também pela AMP, são taxativas ao referirem que as revistas devem reduzir o ênfase no fator de impacto como única medida da qualidade da revista, e adotar também uma gama mais alargada de métricas que sejam tão ou mais relevantes para os leitores e autores. ${ }^{3}$

3. International Committee of Medical Journal Editors. Recommendations for the conduct, reporting, editing, and publication of scholarly work in medical journals. [consultado 2020 Ago 19]. Disponível em: http://www. icmje.org/icmje-recommendations.pdf. 